\title{
A Study on Connotative Development of Local Agricultural Colleges and Universities
}

\author{
Lin Lin \\ Institute of Higher Education, Jilin Agricultural University Jilin 130118, China \\ 775750416@qq.com
}

\begin{abstract}
Keywords: Agricultural Colleges and Universities; Connotative Development; Talents Dividend; Development
\end{abstract}

\begin{abstract}
Under new historical conditions of higher education reform, local agricultural colleges and universities are facing some urgent issues listed as below: how they can gain a foothold in educational reform; how they realize their own connotative development and meet requirements of national major strategies as well; and how to enhance efficiency of school running and provide more "talents dividend" for the development of "agriculture, rural area and farmers" and for the realization of agricultural modernization. Connotative development, as an indispensable development pattern in changing our country from a large higher education nation into a higher education powerhouse [1], aims at improving the quality of talent cultivation and cultivating more and better talents for social development. Under new historical conditions of higher education reform, local agricultural colleges and universities are facing some urgent issues listed as below: how they can gain a foothold in educational reform; how they realize their own connotative development and meet requirements of national major strategies as well; and how to enhance efficiency of school running and provide more "talents dividend" for the development of "agriculture, rural area and farmers" and for the realization of agricultural modernization.
\end{abstract}

\section{The Internal Logic between Connotative Development and Talents Dividend of Local Agricultural Colleges and Universities}

\subsection{Connotative development is the essential requirement for school running of local agricultural colleges and universities}

Connotative development of universities refers to deeply digging or cultivating the internal resources of the universities, promoting its developmental potential and boosting its sustainable and scientific devolopment. If the extensional development is regarded as an imitating development, then the connotative development is an innovative development ${ }^{[3]}$. With the further reform of higher education, people are paying more attention to the promotion of school-running quality and characteristic development, which has already become the developmental directions of universities running. Only when local agricultural colleges and universities insist on the way of connotative development, pursuing qualities and features, can they meet the demands of national major strategies and keep its scientific development. Therefore, connotative development is a basic requirement for school running of agricultural colleges and universities.

\subsection{Connotative development of local agricultural colleges and universities is a fundamental way of improving the development of talents dividend.}

The core question of connotative development of local agricultural colleges and universities is to enhance the quality of school running ${ }^{[5]}$. That is to improve the quality of talent cultivation. Only when the quality of talent cultivation is improved can we provide more talents for our society and for the development of "agriculture, rural areas and farmers", thus releasing a bigger "talents dividend". In this sense, agricultural colleges and universities take the great responsibility of cultivating specialized high-quality talents for agriculture and rural areas. At present, there is a great improvement in teachers' ability, subjects and courses, teaching conditions and capacity for scientific research of local agricultural colleges and universities. But it still can't meet the requirements for development of agriculture and rural areas. There is a long distance from general requirement of 
higher educational reform. Thus local agricultural colleges and universities would develop a bigger talent dividend only by connotative development which is also the most fundamental way.

\subsection{The development of "talent dividend" boosts connotative development of local agricultural colleges and universities.}

The development of "talents dividend" in local agricultural colleges and universities includes the "students talents dividend" and "teachers talents dividend". With good development of the "students talents dividend", local agricultural colleges and univerisites would cultivate more talents for our society and for "agriculture, rural area and farmers", which would gain greater social benefits. Besides, with the good development of "teachers talents dividend", the universities will not only improve the present teaching level and professional proficiency but also attract more excellent teachers to come to the first line of education, which will contribute to the promotion of educational quality and connotative development of universities.

\section{Basic Ways of Connotative Development of Local Agricultural Colleges and Universities.}

\subsection{Take the reform of talent cultivation pattern as the breakthrough point}

Ji Lin Agricultural University always takes promoting the quality of undergraduate teaching and talent cultivation as a basic starting point - strengthening the construction of curriculum system; boosting reform of system mechanism; positively exploring a diversified pattern of talent cultivation with "top-notch talents" cutivation as its core; promoting the comprehensive reform of teaching part and improving the students' comprehensive quality and capacity.

\subsubsection{Optimizing talent cultivation program}

Specific implementation can be listed as a full investigation of talents requirement, construction of five stages of practical innovation, continuous perfection of teaching practice system of modularity, layering and systemization, positive expansion of students' choices, and general optimization of talent cultivation program. Universities need to regularly revise talent cultivation program to make it more suitable for social requirements, educational regulation and school-running orientations.

\subsubsection{Promoting the reform of talent cultivation pattern}

Our university, which regards the first batch of undergraduates enrollment as a chance, takes the requirements for the comprehensive reform pilot, positively explores the pattern of top-notch talent cultivation. We chose Animal Medical Science, Food Science and Engineering and Plant Protection as the three reform majors, constructing a cultivation pattern of" $3+1$ "and " $3+2+3$ " by collecting our best teaching resources, aiming at cultivating top-notch innovative talents. Guided by the demands of job market for talents, our university and An Hua Insurance Company established An Hua College, which has made lots of cooperations in talent cultivation, scientific research and staffs ' training.

\subsubsection{Enhancing the conformity of talent cultivation and social demands}

Our university insists the principle of "win-win cooperation" and it is also the first, among the agricultural colleges and universities, to establish board of directors school-running system - Pooling resources, improving teaching conditions, building teaching staff of full-time and part-time teachers; absorbing the board of directors to participate in the revision of talent cultivation program and the design of important reform project, which provide a strong support for the training of high-quality talent to meet social demands. Our university is the first to establish the school-enterprise joint schoolrunning board of directors in national agricultural colleges and colleges, which has formed a relatively improved operation mechanisms of talent cultivation, teacher training, and science and technology services.

\subsubsection{Improving the teaching quality guarantee and supervising system}

Our university takes the following measures to guarantee the quality of teaching and talent cultivation - strengthening two levels of college and university teaching and supervision team building, establishing and improving the quality standards of each teaching link, improving the system of teacher evaluation, promoting the improvement of the quality supervising system with multi-subjects to participation, which forms long-term effective mechanism of undergraduate teaching quality assurance regularly, systematically and entirely. 


\subsection{Regard the optimization of discipline and major setting as the breakthrough point}

In the course of school-running, our university takes a great importance of policies, taking the initiative to adapt to the demands of economic construction and social development for the talent cultivation; constantly optimizing discipline and major setting and revising the major structure scientifically, which forms the butt joint of dominant characteristic disciplines and local predominant industries. Our university actively adds new majors and forms a group of disciplines which is characterized by taking agriculture as advantages and characteristics and combined with science, engineering, medicine, art, management, law, and education as well, promoting the connotative development of the university.

\subsubsection{Relying on the advantages of local resources and cultivating agriculture-related majors} based on industry adjustment.

Relying on the resources advantages of Jilin major grain producing area and Chinese herbal medicine, our university set up many majors closely related to local economic development of Jilin province such as Agricultural Machinery and Design, Corn Deep Processing, Chinese Medicine Resources and Development, Economic Animals, Green Food Production. Combined with the present condition of city construction and ecological environment of Jilin Province, our university set up some majors related to strategic industries such as environmental science, environmental engineering, new energy science and engineering, actively responding to ecological rural construction.

\subsubsection{Facing regional development and creating dominant and characteristic displines}

Facing regional development of Jilin Province and surrounding local economic construction, the regional specialty resources of Changbai Mountain, the advantages of "golden corn belt" and the actual situation of desertification control in western Jilin Province, our university focuses on creating some dorminant and characteristic disciplines such as Agronomy, Veterinary Medicine, Plant Protection. Answering the needs of pillar industries and social development of Jilin Province, our university strengthenes the creation of characteristic research, highlighting the advantage and characteristics in cultivation of good quality and high yield crops, comparative animal nutrition, and biotechnological breeding, which forms dominant and characteristic disciplines and majors.

\subsubsection{Combining social demands with the reality of university and timely adjusting the professional structure and layout}

Our university attaches great importance to the adjustment of professional structure. Aware of the needs of society for talents, it takes full advantage of its present resources. Each adjustment or addition of new major is based on the full consideration of the resources sharing and the overall efficiency of school-running, which has formed healthy, scientific and coordinated relationship between the professional structure of talent cultivation and resources allocation ${ }^{[2]}$.

\subsection{Regarding the construction of qualified personnel as the fundamental guarantee}

The development of the "talents dividend" in local agricultural colleges and universities includes talent cultivation which means the development of "students talent dividend" and the construction of teaching staff which means the development of "teachers talent dividend". The development of "teachers talent dividend" is basis and guarantees and the premise of development of "students talent dividend". Only a high-level faculty can guarantee the cultivation of outstanding talents. Our university always adheres the strategy of "developing the university by relying on talents." Based on the principles of improving the total number, optimizing the professional structure and promoting scientific development of discipline echelon, the university effectively increased the number of teachers by the introduction of high-level talents and annual open recruitment. The overall number of teaching staff was increased gradually by introducing the high-level talents of national thousands plan and recruiting doctor and master graduates.

\subsubsection{Leading teachers to the professional growth.}

Our university encourages more teachers to continue their further study either by getting a higher degree or as visiting scholars. The school-based training is well developed to reinforce the course construction of training programs, combining the modern science and technology of brain science, education, psychology and informatics into the programs to make the training well-prepared, scientific and effective. Teachers are guided to study teaching and improve it by "learning in the 
practice, in the context and in the reflection of their teaching". Attaching great importance to the classroom teaching and management, they will realize their professional growth by impoving their professional expertise and teaching level.

\subsubsection{Enhancing the cultivation of teachers}

Special funds are launched for the cultivation of teachers. The two-level of college-university administration system of funds is established, regularly selecting and sending the young and middleaged teachers to have advanced studies. The backbone teachers are especially singled out and sent to famous universities and research institutes abroad for academic exchange, scholarly visiting or advanced study. Other teachers are sent to domestic higher-level universities, famous research institutes or enterprises to have short or long term training. The multi-channel training has improved the overall quality of teaching staff.

\subsubsection{Building a platform for teachers'growth}

Our university attaches great importance to the improvement of teachers' professional expertise and ability, carrying out the research work of teaching education and instruction, and organizing the professional seminars to build a platform for teachers' growth. Furthermore, our university strengthens the research items of teaching education and instruction, and encourages teachers to carry out teaching research and academic activities. Through various activities of the "Reform and Development of Higher Education" forum, the academic exchange conferences of higher education research, the training program for higher education research, the research achievements academic seminar of higher education teaching and instruction, and part-time or full-time researchers symposium, a new platform is built for the active academic atmosphere for higher education research, which provides the platform for teachers' growth.

\section{Conclusion}

The connotative development is regarded as an inevitable way for the local colleges and universities to enhance the school-running quality. Only by reforming the pattern of talents cultivation, optimizing discipline and major setting and strengthening the construction of qualified personnel can the local colleges and universities enhance their endogenous power, realize the connotative development and cultivate more research-oriented talents, inter-disciplinary talents and applicationoriented talents for the development of agriculture.

\section{References}

[1]. Guo Guangyin. Lay a More Solid Foundation for Construction of First-class University by Means of Connotative Development[J]. China Higher Education, 2013(7):4-6.

[2]. Hu Changgui. On Strategic Choices of Implementation of Connotative Development in Colleges and Universities[J]. Journal of Changchun University of Technology, 2007(1):61-64.

[3]. Lin Lin, Yu Yanhua. Research on Connotative Development of Local Agricultural Colleges and Universities under New Situations[J]. Education and Vocation, 2013(33): 24-25.

[4]. Shi Ningguo. What Should We Depend on to "Create Talent Dividend"[J]. China Education Daily, 2014(3):17.

[5]. Xie Renye. Connotative Development of China Higher Education: Value, Problem and Trend [J]. Education Development Research, 2006, (7):7-10. 